\title{
Catalyst-Free Click Polymerization of Thiol and Activated Internal Alkynes: A Facile Strategy toward Functional Poly( $\beta$-thioacrylate)s
}

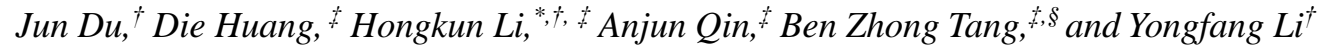 \\ ${ }^{\dagger}$ State and Local Joint Engineering Laboratory for Novel Functional Polymeric Materials, \\ Laboratory of Advanced Optoelectronic Materials, College of Chemistry, Chemical Engineering \\ and Materials Science, Soochow University, Suzhou 215123, China \\ ${ }^{*}$ State Key Laboratory of Luminescent Materials and Devices, Key Laboratory of Luminescence \\ from Molecular Aggregates of Guangdong Province, Center for Aggregation-Induced Emission, \\ South China University of Technology, Guangzhou, 510640, China \\ ${ }^{\S}$ Department of Chemistry, Hong Kong Branch of Chinese National Engineering Research Center \\ for Tissue Restoration and Reconstruction, The Hong Kong University of Science \& Technology, \\ Clear Water Bay, Kowloon, Hong Kong, China
}

Table of Contents

Scheme S1. Synthetic route to monomers $\mathbf{2 a - c .}$

Figure S1. IR spectra of monomers $2 \mathbf{b}(\mathrm{A})$ and $\mathbf{1}$ (B) and their polymer P1/2b (C). S3

Figure S2. IR spectra of monomers $2 c(A)$ and $\mathbf{1}$ (B) and their polymer P1/2c (C). S4

Figure S3. IR spectra of monomers 3a (A) and 1 (B) and their polymer P1/3a (C). S4

Figure S4. IR spectra of monomers $\mathbf{3 b}(\mathrm{A})$ and $\mathbf{1}$ (B) and their polymer P1/3b (C). S5

Figure S5. IR spectra of monomers 3c (A) and 1 (B) and their polymer P1/3c (C). S5 
Figure S6. ${ }^{1} \mathrm{H}$ NMR spectra of monomers $\mathbf{2 b}(\mathrm{A})$ and $\mathbf{1}$ (B) and their polymer P1/2b

(C) in $\mathrm{CDCl}_{3}$. The solvent and water peaks are marked with asterisks.

Figure S7. ${ }^{1} \mathrm{H}$ NMR spectra of monomers $2 \mathrm{c}(\mathrm{A})$ and 1 (B) and their polymer P1/2c

(C) in $\mathrm{CDCl}_{3}$. The solvent and water peaks are marked with asterisks.

Figure S8. ${ }^{1} \mathrm{H}$ NMR spectra of monomers $\mathbf{3 a}(\mathrm{A})$ and $\mathbf{1}(\mathrm{B})$ and their polymer P1/3a

(C) in $\mathrm{CDCl}_{3}$. The solvent and water peaks are marked with asterisks.

Figure S9. ${ }^{1} \mathrm{H}$ NMR spectra of monomers $\mathbf{3 b}(\mathrm{A})$ and $\mathbf{1}(\mathrm{B})$ and their polymer P1/3b

(C) in $\mathrm{CDCl}_{3}$. The solvent and water peaks are marked with asterisks.

Figure S10. ${ }^{1} \mathrm{H}$ NMR spectra of monomers $\mathbf{3 c}(\mathrm{A})$ and $\mathbf{1}(\mathrm{B})$ and their polymer P1/3c

(C) in $\mathrm{CDCl}_{3}$. The solvent and water peaks are marked with asterisks.

S8

Figure S11. ${ }^{13} \mathrm{C}$ NMR spectra of monomers $\mathbf{2 b}(\mathrm{A})$ and $\mathbf{1}(\mathrm{B})$ and their polymer P1/2b

(C) in $\mathrm{CDCl}_{3}$. The solvent peaks are marked with asterisks.

S8

Figure S12. ${ }^{13} \mathrm{C}$ NMR spectra of monomers $2 \mathrm{c}(\mathrm{A})$ and $\mathbf{1}(\mathrm{B})$ and their polymer $\mathrm{P} \mathbf{1} / \mathbf{2 c}$

(C) in $\mathrm{CDCl}_{3}$. The solvent peaks are marked with asterisks.

Figure S13. ${ }^{13} \mathrm{C}$ NMR spectra of monomers 3a (A) and $\mathbf{1}(\mathrm{B})$ and their polymer P1/3a

(C) in $\mathrm{CDCl}_{3}$. The solvent peaks are marked with asterisks.

Figure S14. ${ }^{13} \mathrm{C}$ NMR spectra of monomers $\mathbf{3 b}(\mathrm{A})$ and $\mathbf{1}(\mathrm{B})$ and their polymer $\mathrm{P} \mathbf{1} / \mathbf{3 b}$

(C) in $\mathrm{CDCl}_{3}$. The solvent peaks are marked with asterisks.

S10

Figure S15. ${ }^{13} \mathrm{C}$ NMR spectra of monomers $3 \mathrm{c}(\mathrm{A})$ and $\mathbf{1}$ (B) and their polymer P1/3c

(C) in $\mathrm{CDCl}_{3}$. The solvent peaks are marked with asterisks.

S10

Figure S16. DSC curves of $\mathrm{P} 1 / 2 \mathbf{a}-\mathbf{c}$ and $\mathrm{P} 1 / 3 \mathbf{a}-\mathbf{c}$ measured under nitrogen at a scanning rate of $2^{\circ} \mathrm{C} / \mathrm{min}$.

S11

Table S1. Refractive indices, Abbé numbers and chromatic dispersions of thin films of the PTAs. 


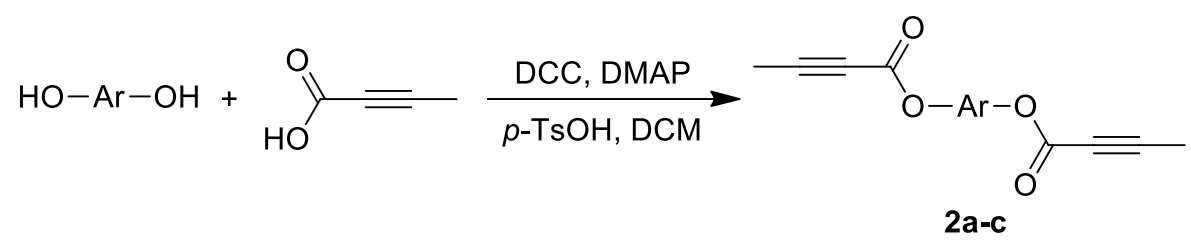

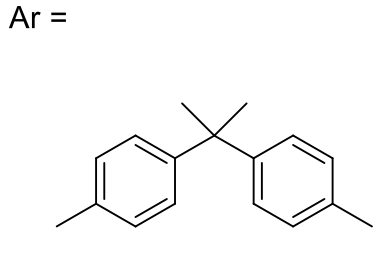

a

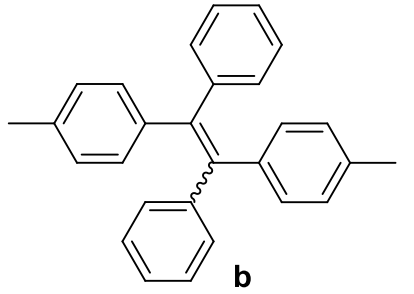

b

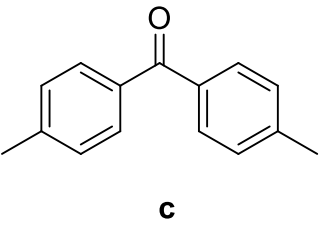

C

Scheme S1. Synthetic route to monomers $\mathbf{2 a - c .}$
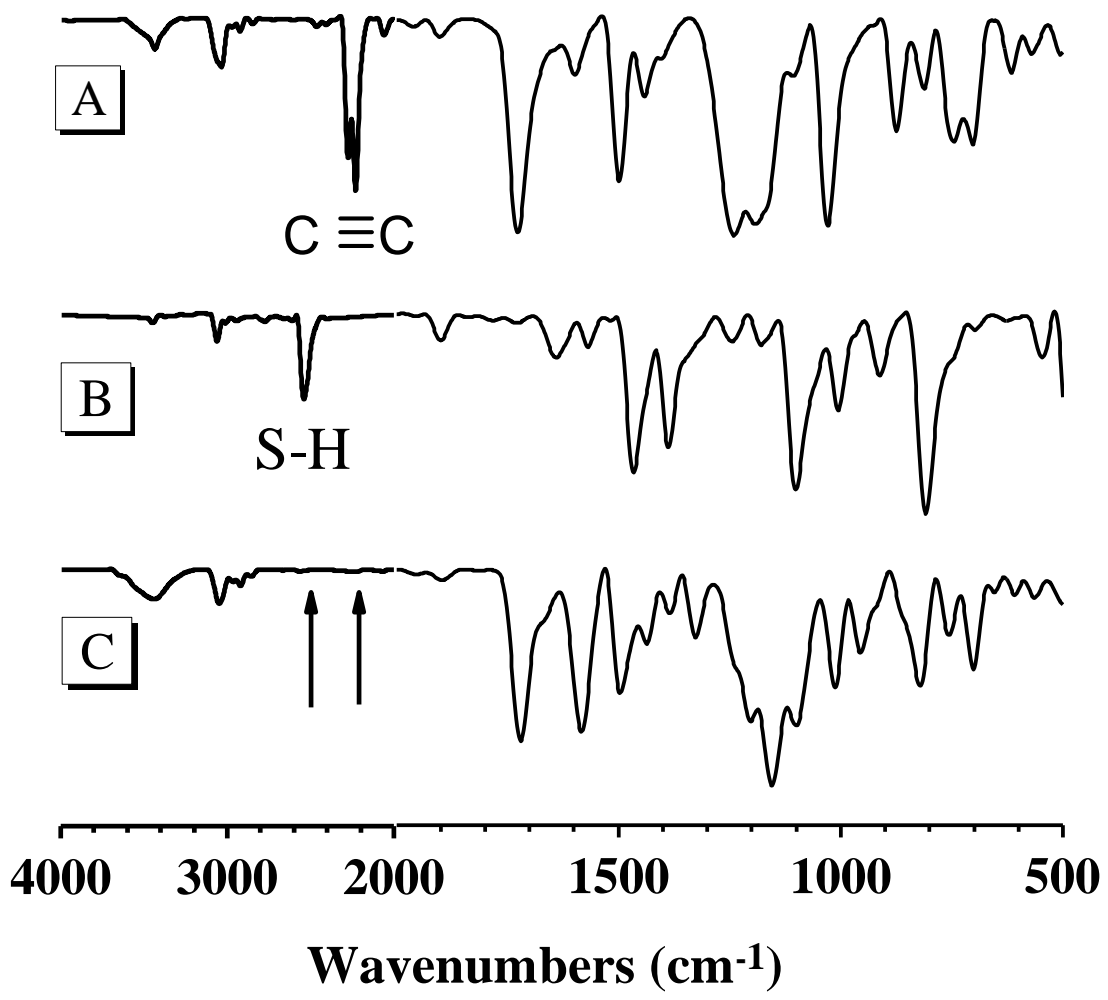

Figure S1. IR spectra of monomers $\mathbf{2 b}(\mathrm{A})$ and $\mathbf{1}(\mathrm{B})$ and their polymer P1/2b (C). 

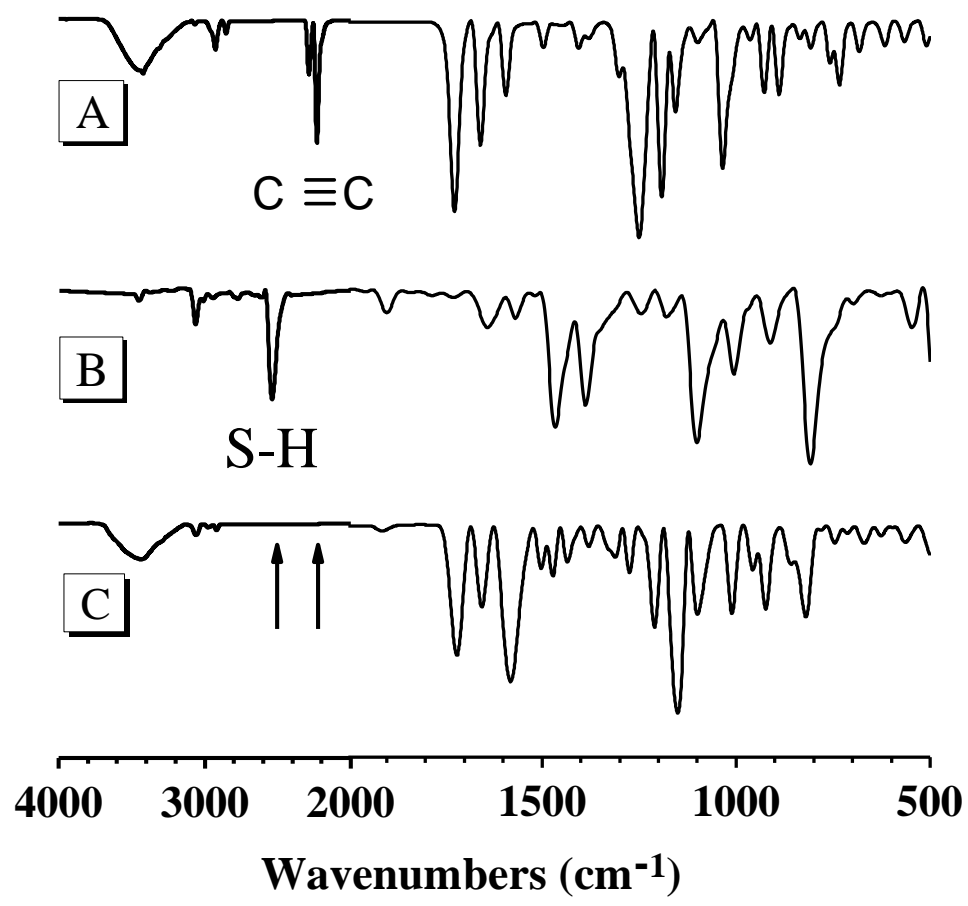

Figure S2. IR spectra of monomers 2c (A) and 1 (B) and their polymer P1/2c (C).
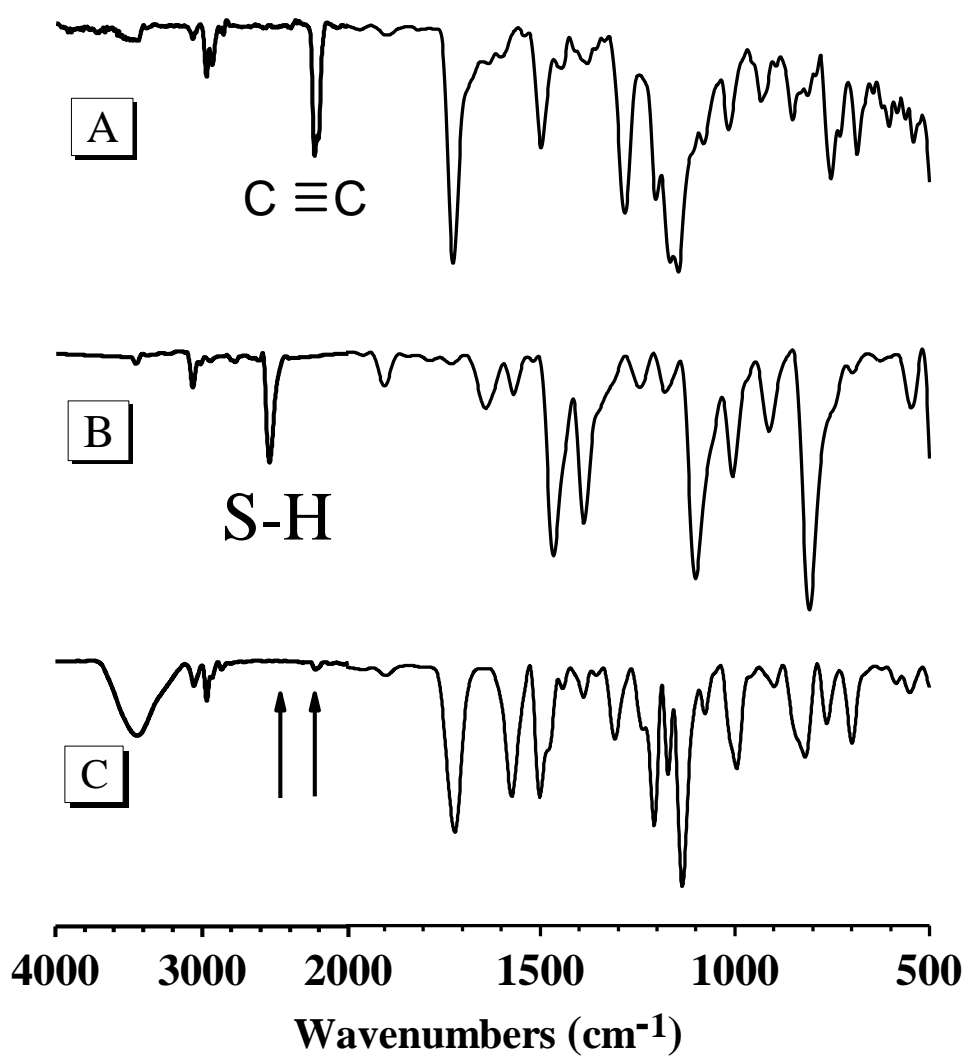

Figure S3. IR spectra of monomers 3a (A) and 1 (B) and their polymer P1/3a (C). 

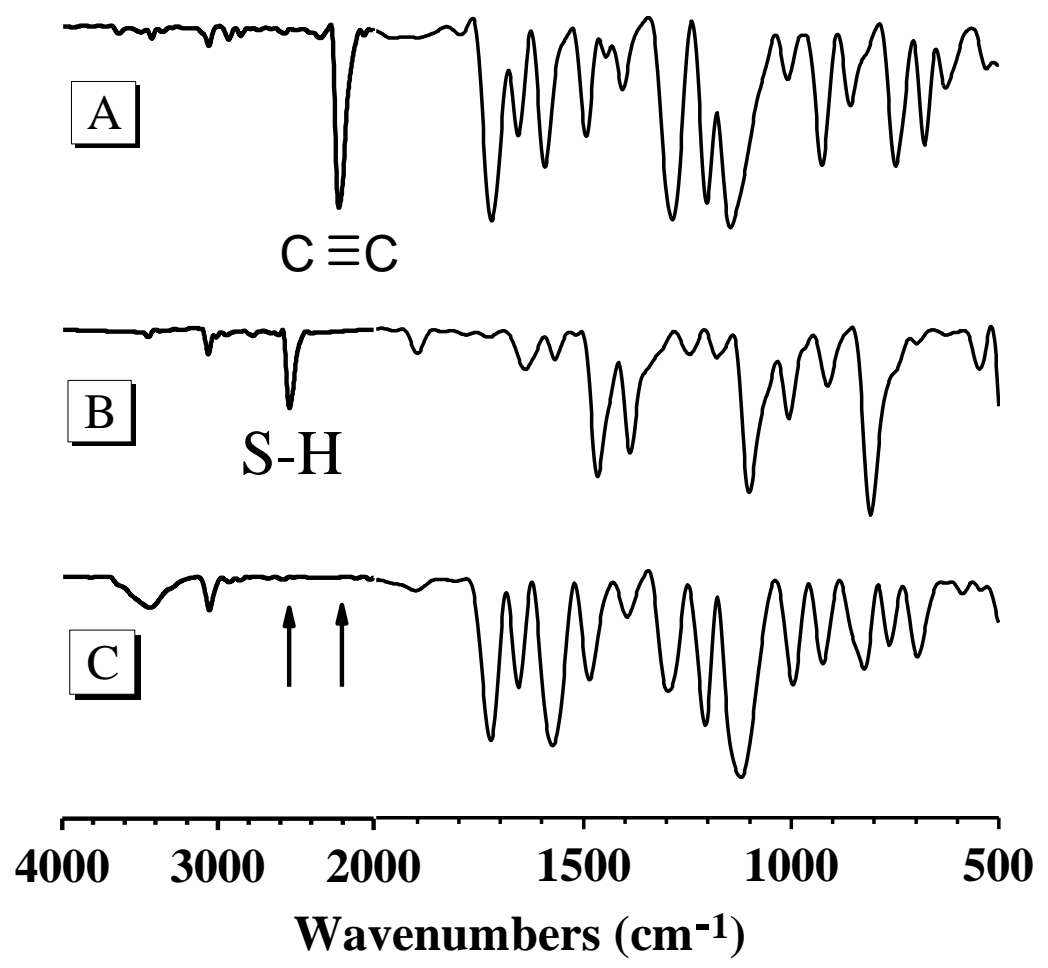

Figure S4. IR spectra of monomers $\mathbf{3 b}(\mathrm{A})$ and $\mathbf{1}$ (B) and their polymer P1/3b (C).
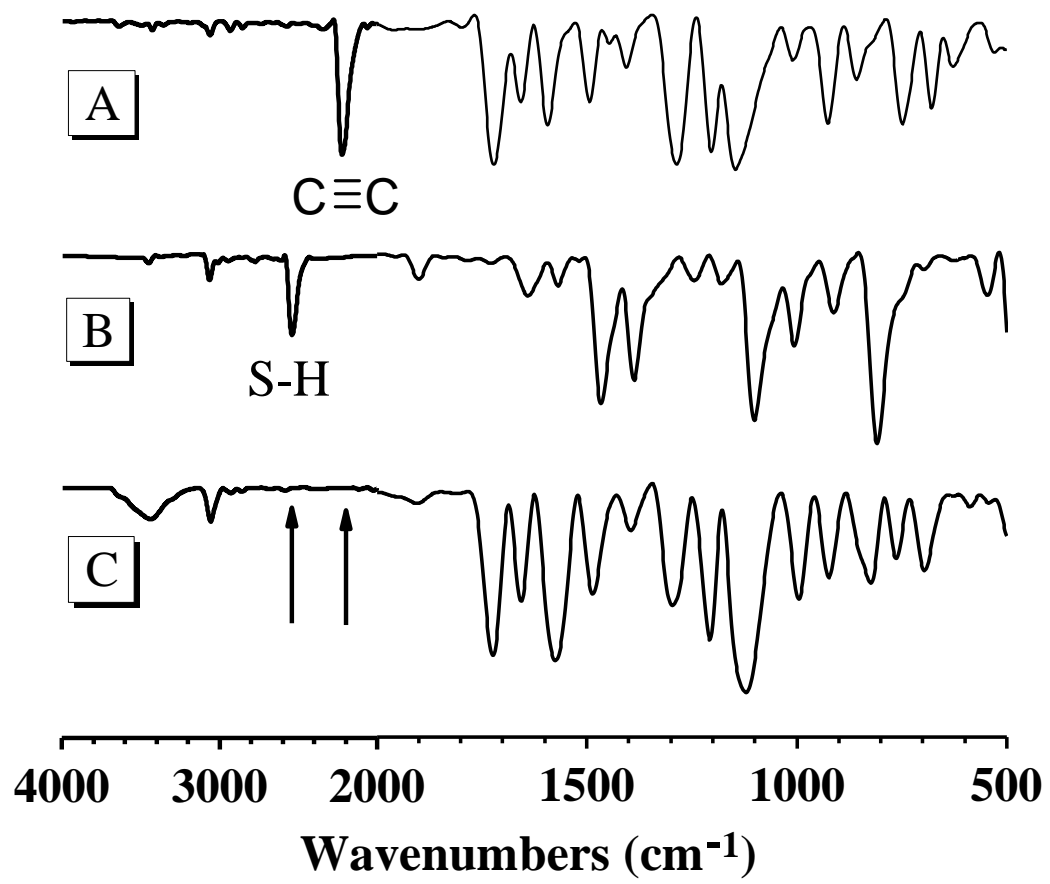

Figure S5. IR spectra of monomers 3c (A) and 1 (B) and their polymer P1/3c (C). 


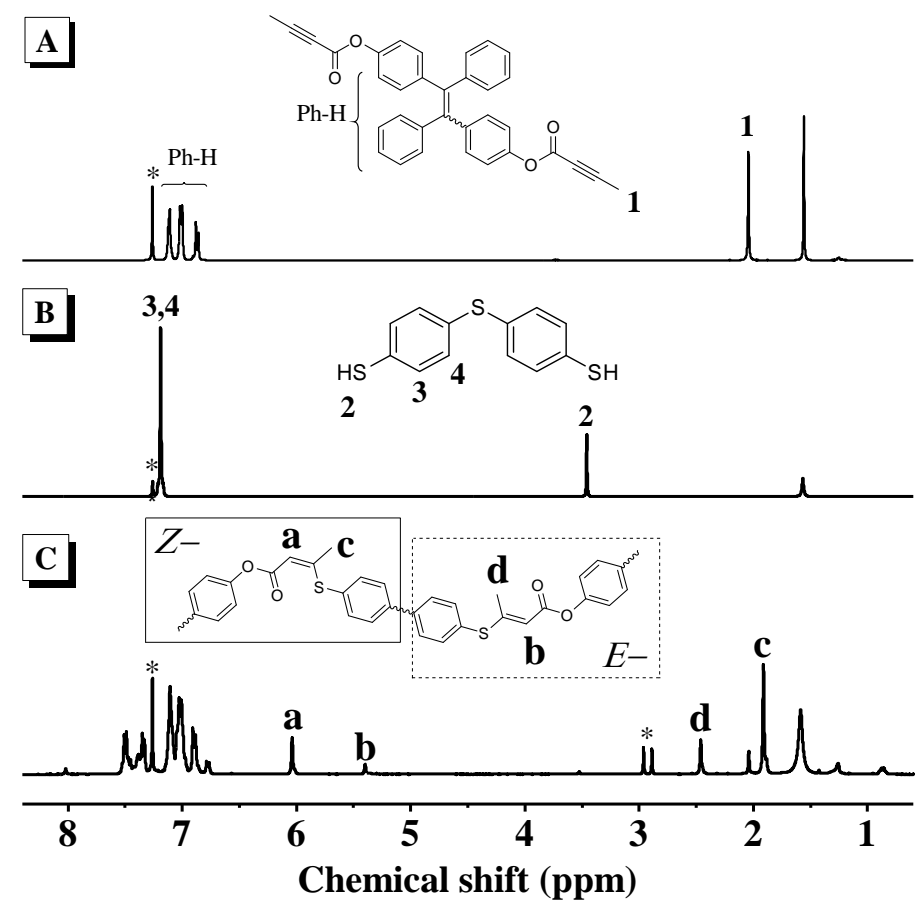

Figure S6. ${ }^{1} \mathrm{H}$ NMR spectra of monomers $2 \mathbf{b}(\mathrm{A})$ and $\mathbf{1}(\mathrm{B})$ and their polymer $\mathrm{P} \mathbf{1} / \mathbf{2 b}(\mathrm{C})$ in $\mathrm{CDCl}_{3}$. The solvent and water peaks are marked with asterisks.

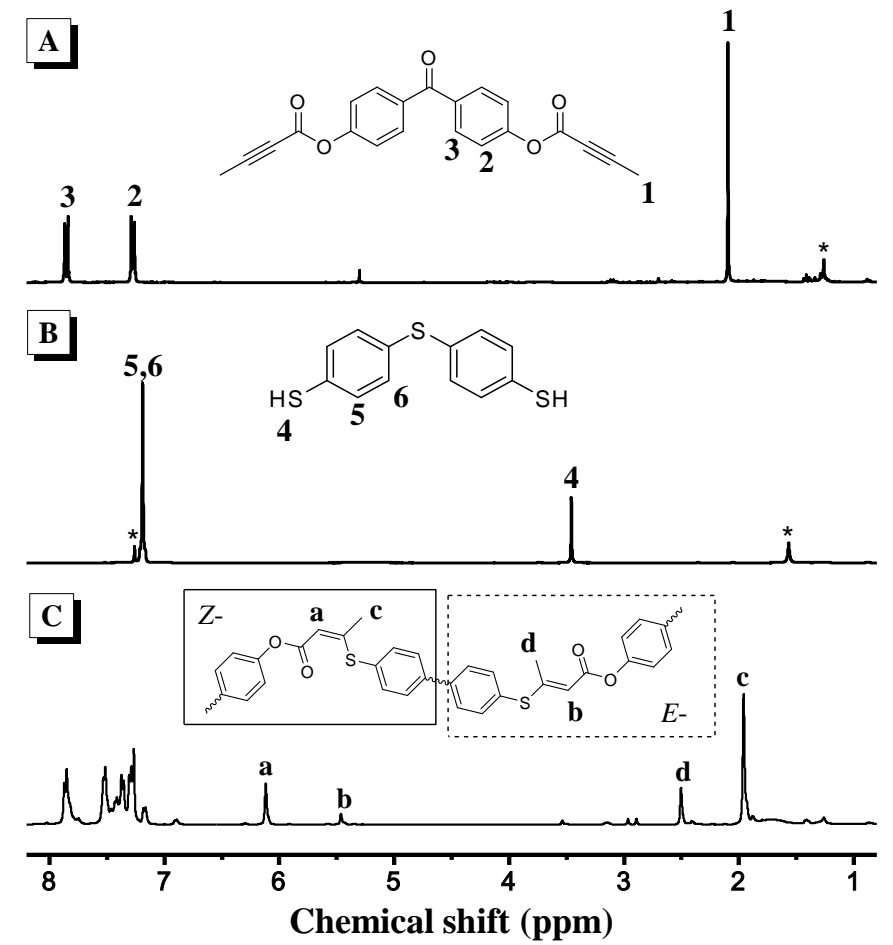

Figure S7. ${ }^{1} \mathrm{H}$ NMR spectra of monomers $2 \mathrm{c}(\mathrm{A})$ and $\mathbf{1}$ (B) and their polymer $\mathrm{P} \mathbf{1} / \mathbf{2} \mathbf{c}(\mathrm{C})$ in $\mathrm{CDCl}_{3}$. The solvent and water peaks are marked with asterisks. 


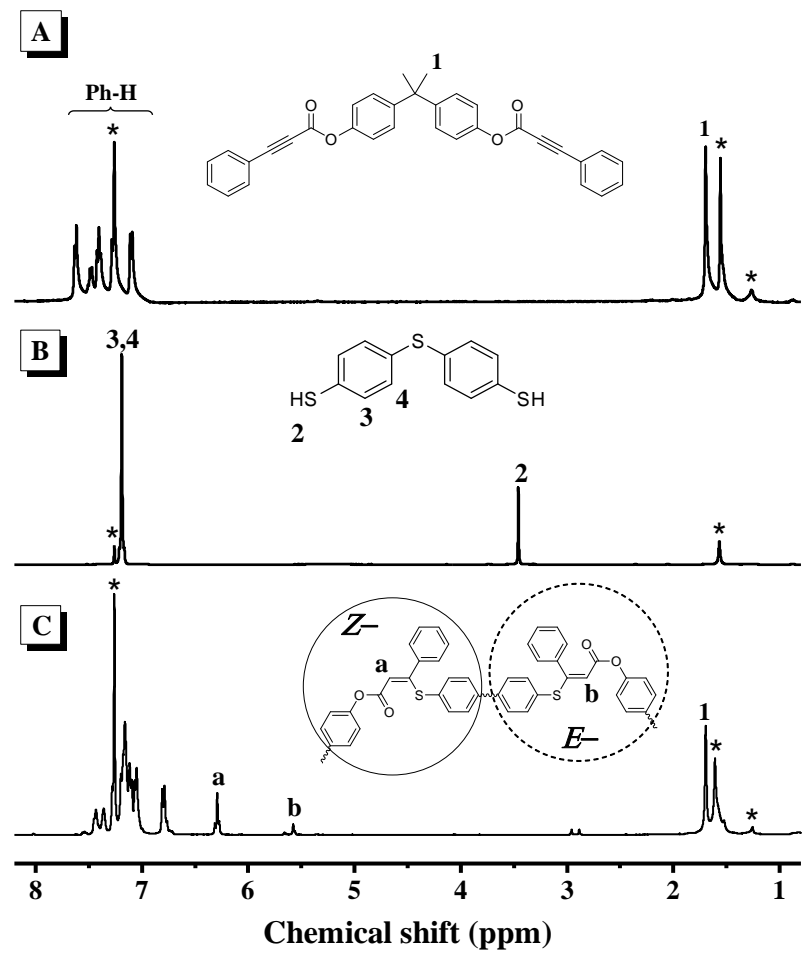

Figure S8. ${ }^{1} \mathrm{H}$ NMR spectra of monomers $3 \mathbf{a}(\mathrm{A})$ and $\mathbf{1}(\mathrm{B})$ and their polymer $\mathrm{P} \mathbf{1} / \mathbf{3 a}(\mathrm{C})$ in $\mathrm{CDCl}_{3}$. The solvent and water peaks are marked with asterisks.

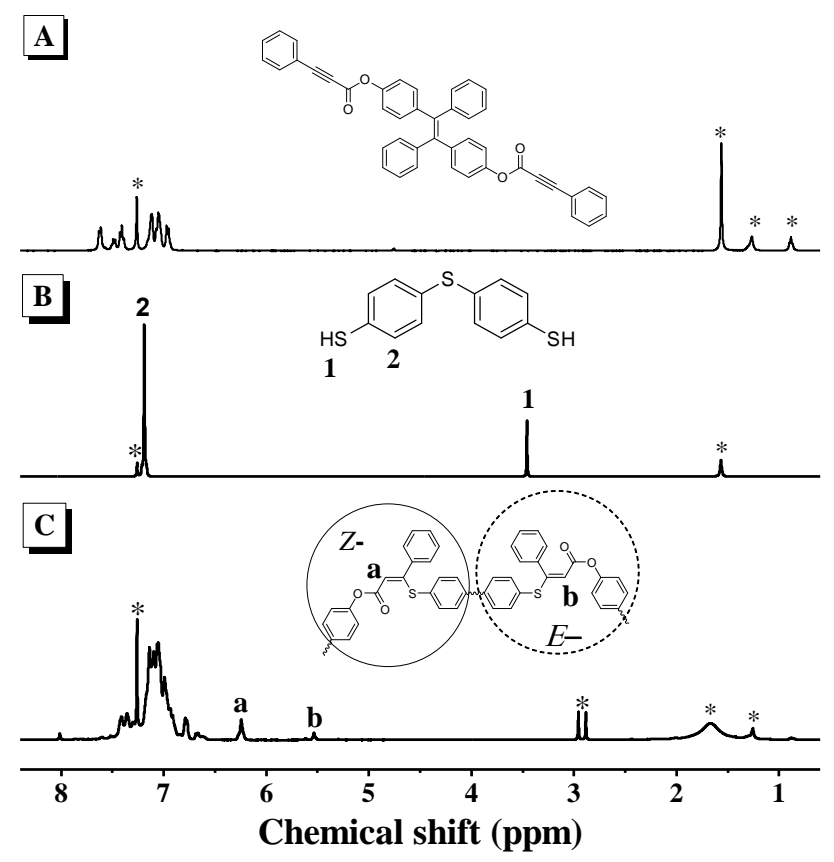

Figure S9. ${ }^{1} \mathrm{H}$ NMR spectra of monomers $3 \mathbf{b}(\mathrm{A})$ and $\mathbf{1}(\mathrm{B})$ and their polymer $\mathrm{P} \mathbf{1} / \mathbf{3 b}(\mathrm{C})$ in $\mathrm{CDCl}_{3}$. The solvent and water peaks are marked with asterisks. 

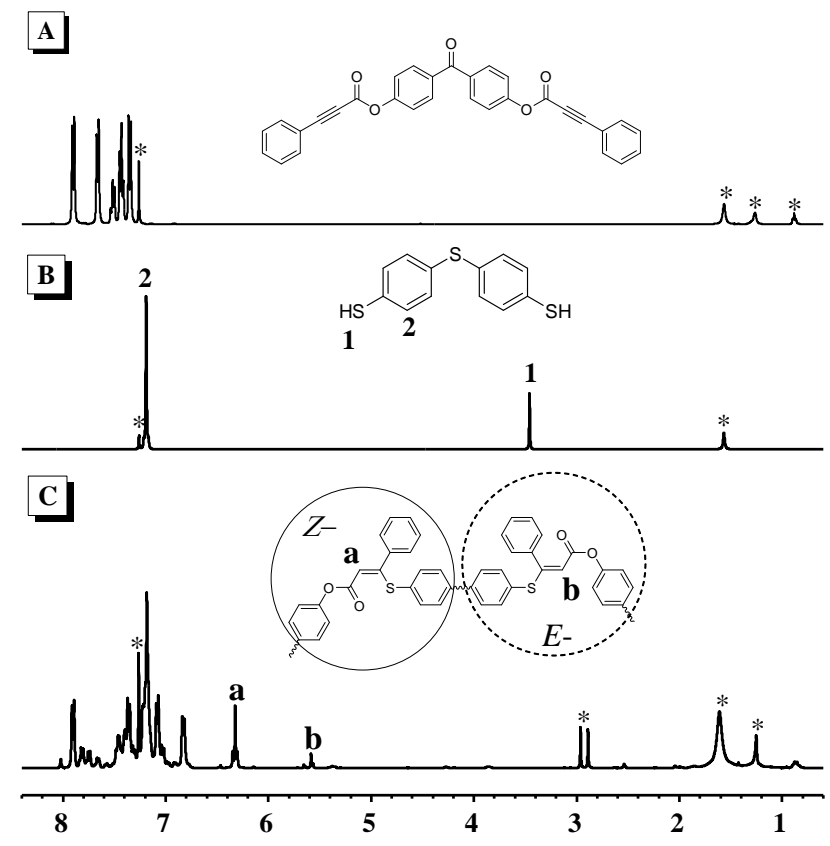

Chemical shift (ppm)

Figure S10. ${ }^{1} \mathrm{H}$ NMR spectra of monomers $3 \mathbf{c}(\mathrm{A})$ and $\mathbf{1}$ (B) and their polymer $\mathrm{P} \mathbf{1} / \mathbf{3 c}(\mathrm{C})$ in $\mathrm{CDCl}_{3}$. The solvent and water peaks are marked with asterisks.

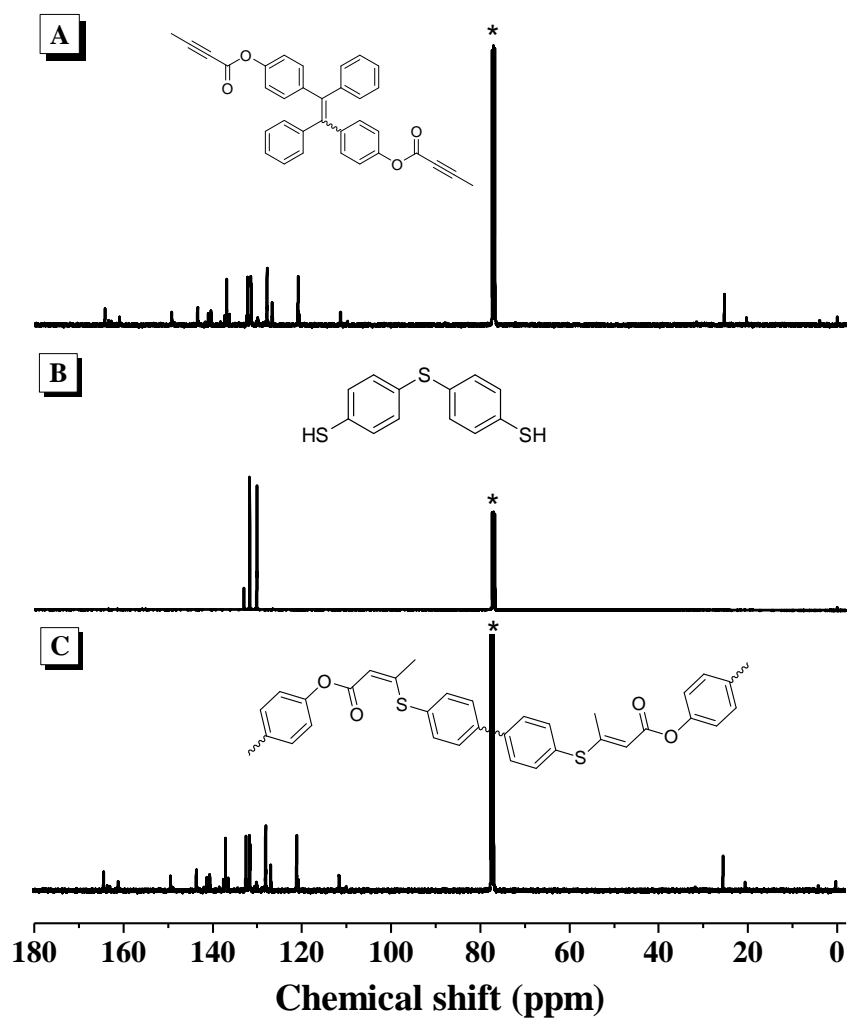

Figure S11. ${ }^{13} \mathrm{C}$ NMR spectra of monomers $2 \mathrm{~b}(\mathrm{~A})$ and $\mathbf{1}(\mathrm{B})$ and their polymer P1/2b (C) in $\mathrm{CDCl}_{3}$. The solvent peaks are marked with asterisks. 


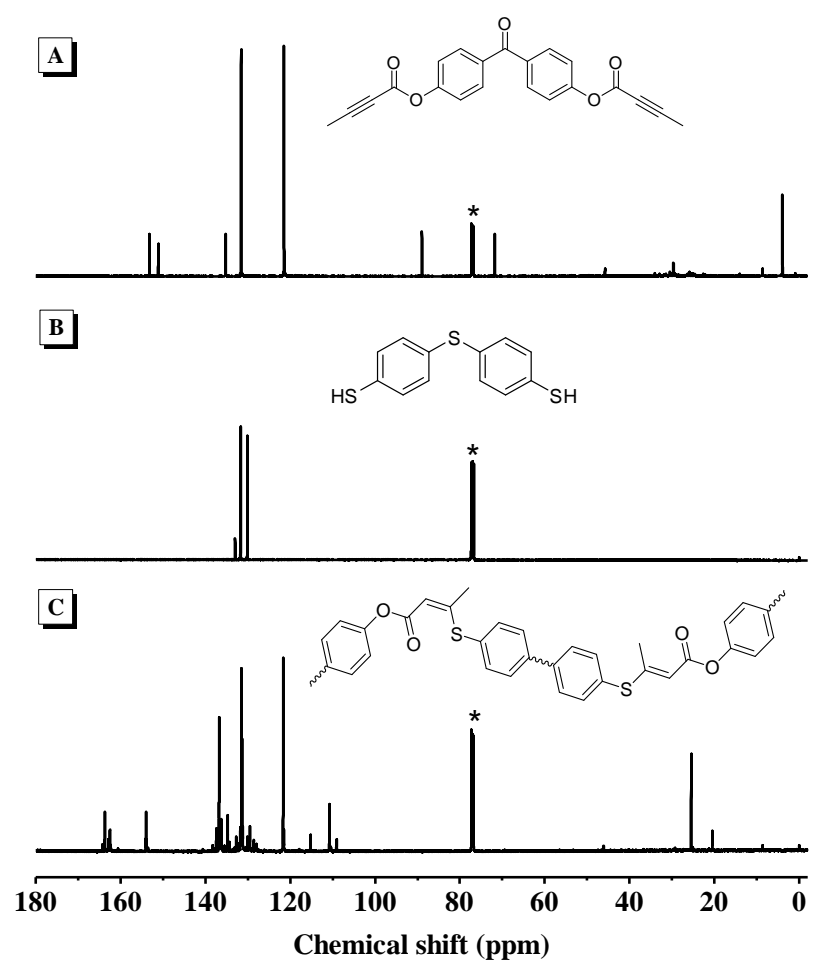

Figure S12. ${ }^{13} \mathrm{C}$ NMR spectra of monomers $2 \mathbf{c}(\mathrm{A})$ and $\mathbf{1}$ (B) and their polymer P1/2c (C) in $\mathrm{CDCl}_{3}$. The solvent peaks are marked with asterisks.

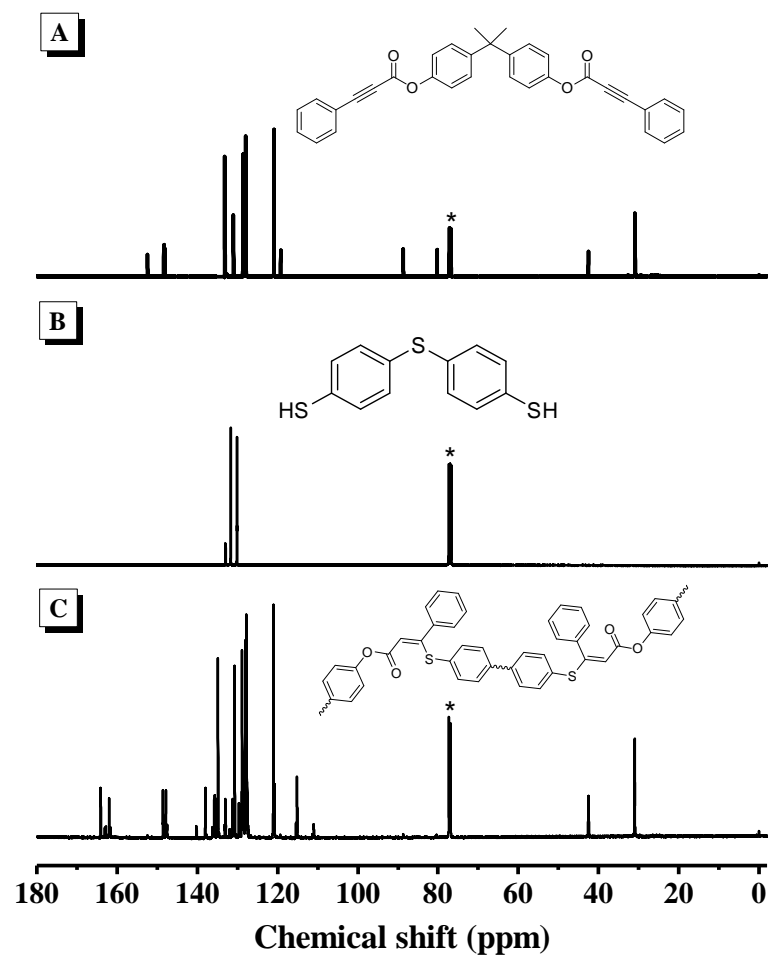

Figure S13. ${ }^{13} \mathrm{C}$ NMR spectra of monomers 3a (A) and $\mathbf{1}(\mathrm{B})$ and their polymer P1/3a (C) in $\mathrm{CDCl}_{3}$. The solvent peaks are marked with asterisks. 


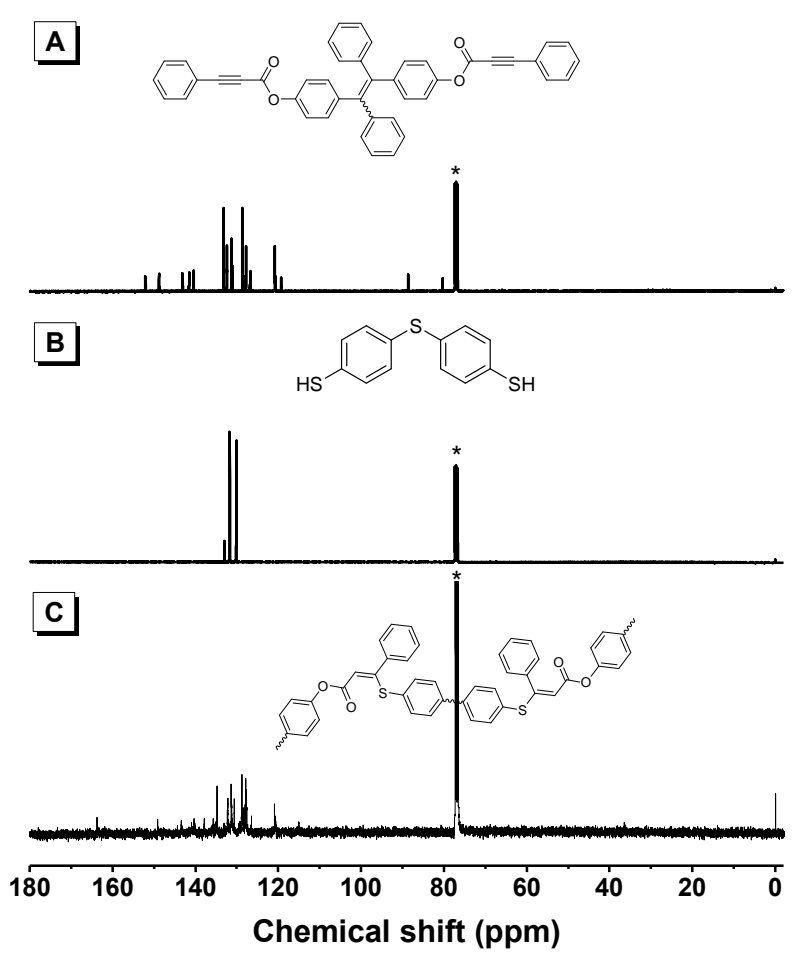

Figure S14. ${ }^{13} \mathrm{C}$ NMR spectra of monomers $3 \mathrm{~b}(\mathrm{~A})$ and $\mathbf{1}(\mathrm{B})$ and their polymer $\mathrm{P} \mathbf{1} / \mathbf{3 b}(\mathrm{C})$ in $\mathrm{CDCl}_{3}$. The solvent peaks are marked with asterisks.

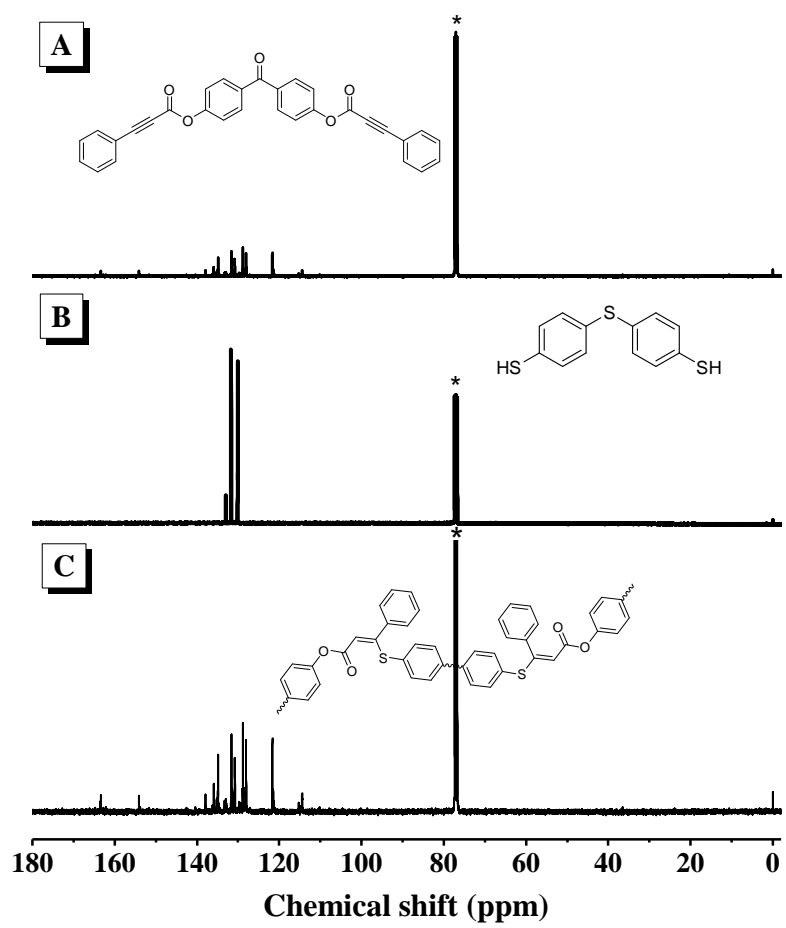

Figure S15. ${ }^{13} \mathrm{C}$ NMR spectra of monomers $3 \mathrm{c}(\mathrm{A})$ and $\mathbf{1}(\mathrm{B})$ and their polymer $\mathrm{P} \mathbf{1 / 3 c}(\mathrm{C})$ in $\mathrm{CDCl}_{3}$. The solvent peaks are marked with asterisks. 


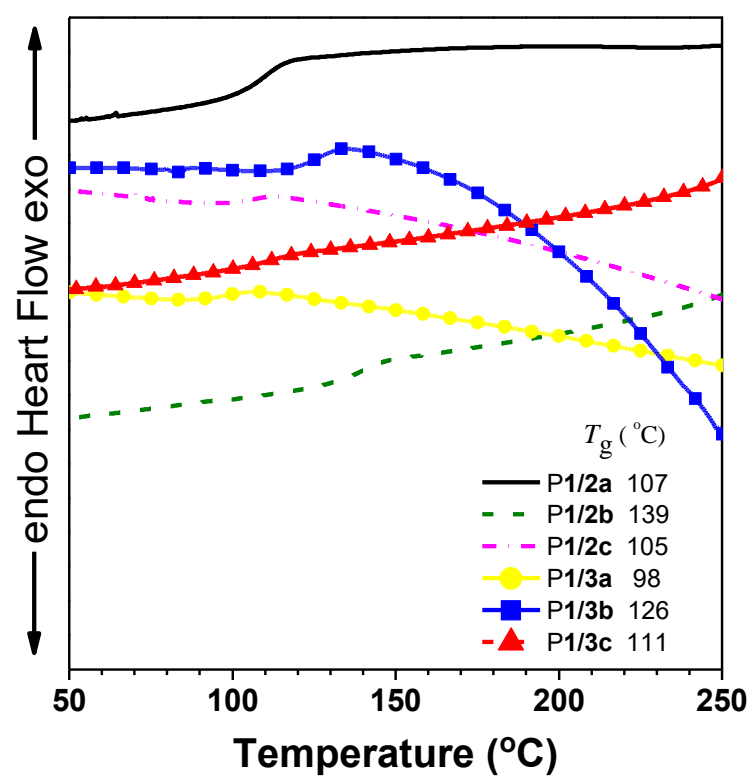

Figure S16. DSC curves of $\mathrm{P} \mathbf{1} / \mathbf{2 a}-\mathbf{c}$ and $\mathrm{P} \mathbf{1} / \mathbf{3 a}-\mathbf{c}$ measured under nitrogen at a scanning rate of 2 ${ }^{\circ} \mathrm{C} / \mathrm{min}$.

Table S1. Refractive indices, Abbé numbers and chromatic dispersions of thin films of the PTAs ${ }^{a}$

\begin{tabular}{cccccccc}
\hline PTA & $n_{400-1700}$ & $n_{632.8}$ & $n_{1550}$ & $v_{\text {D }}$ & $v_{\mathrm{D}}{ }^{\prime}$ & $D$ & $D^{\prime}$ \\
\hline P1/2a & $1.7638-1.6304$ & 1.6742 & 1.6318 & 15.9 & 69.0 & 0.063 & 0.014 \\
$\mathrm{P} 1 / 2 b$ & $1.8174-1.6574$ & 1.6915 & 1.6581 & 12.8 & 126.9 & 0.078 & 0.008 \\
$\mathrm{P} 1 / 2 \mathbf{c}$ & $1.8316-1.6862$ & 1.7216 & 1.6870 & 15.6 & 114.8 & 0.064 & 0.009 \\
$\mathrm{P} \mathbf{1} / \mathbf{3 a}$ & $1.7845-1.6496$ & 1.6840 & 1.6505 & 15.8 & 110.6 & 0.063 & 0.009 \\
$\mathrm{P} \mathbf{1} / 3 \mathbf{b}$ & $1.8169-1.6654$ & 1.7006 & 1.6662 & 14.6 & 117.2 & 0.068 & 0.009 \\
$\mathrm{P} \mathbf{1} / \mathbf{3 c}$ & $1.8334-1.6761$ & 1.7098 & 1.6768 & 14.3 & 135.7 & 0.070 & 0.007
\end{tabular}

${ }^{a}$ Abbreviations: $n=$ refractive index, $v \mathrm{D}=$ Abbé number, $v \mathrm{D}^{\prime}=$ modified Abbé number, $D=$ chromatic dispersion in the visible region, and $D^{\prime}=$ chromatic dispersion in the IR region. 